EDITORIAL

\title{
Intensive Care Unit Nurses and Ethical Attitudes
}

\author{
Pritee Tarwade
}

Keywords: Ethics, Intensive care unit, Medical education, Moral, Nursing.

Indian Journal of Critical Care Medicine (2022): 10.5005/jp-journals-10071-24161

As the world faces SARS COVID-2 pandemic, the insufficiencies in healthcare across the world are being exposed. It became obvious the number of facilities and manpower in healthcare was inadequate to take care of masses in pandemic of this magnitude. Healthcare teams had to deal with many moral and ethical challenges which they had never dealt with, mainly because of large and persistent inflow of patients. 'Many of them had not seen death to such magnitude in their whole career. Obviously this resulted in emotional and mental fatigue leading to job dissatisfaction along with increasing number of nurses leaving the profession.

There is a great variability in nursing training and responsibilities across the world. Over the years many studies have been done to find source of moral distress and ethical conflicts by the way of questionnaires, but there is still lack of awareness among physicians and nurses about this ethical conflict and certainly not enough is done to solve this problem.

American Association of Critical Care Nurses define moral distress as "a situation when the ethically appropriate action to take is known but one is unable to act upon it, when one acts in a manner contrary to his or her personal or professional values which undermines that individuals integrity and authenticity." ${ }^{2}$ Moral dilemma on the other hand is described as a situation when ethically correct course of action is unknown. Ethical conflict is described by Falco-Pegueroles et al. as a barrier to decision-making process and is derived from ethical responsibilities that nurses assume with care. ${ }^{3}$

Multiple studies including the study published in this issue "Ethical Attitudes of Intensive Care Nurses During Clinical Practice and Affecting Factors" by Can et al. have tried to understand the ethical attitude and conflicts of nurses by means of questionnaire. In this study 350 critical care nurses in Turkey were given questionnaires about their demographics, working hours and experience and state of their ethical problems. Ethical attitude scale for nursing care (Min score 34 and maximum 170) was used as tool to assess the ethical conflicts and attitude. ${ }^{4}$ Lower average scores indicate negative ethical attitudes. The study showed that $70.4 \%$ nurses did not receive any ethics training outside of school and $68.4 \%$ did not attend symposium on ethics. The study showed that score for personnel who did not care for a patient diagnosed with coronavirus were higher. $62.2 \%$ of participants had frequent ethical problems while providing care, $19 \%$ had no ethical problems and $18.7 \%$ were unaware of ethical problems. And $59 \%$ solved their problems themselves, 30.1\% took help of colleagues, $5.5 \%$ took help of other health professionals and $5.5 \%$ failed to solve ethical problems. There was statistically significant relationship between numbers of works worked every week and average scores. Males were found to have higher average scores
Department of Anesthesiology, Medical University of South Carolina, Charleston, South Carolina, United States of America

Corresponding Author: Pritee Tarwade, Department of Anesthesiology, Medical University of South Carolina, Charleston, South Carolina, United States of America, e-mail: priteeat@gmail.com How to cite this article: Tarwade P. Intensive Care Unit Nurses and Ethical Attitudes. Indian J Crit Care Med 2022;26(3):259-260.

Source of support: Nil

Conflict of interest: None

than females. There was no statistically significant relationship between the average scores and marital status, position worked in ICU, status of ethics training, shifts worked in, number of nurses, educational status, age of patient and duration of work in profession.

This study participants were asked to define ethics and $75 \%$ of the participants defined it as "justice, causing no harm, autonomy, being fair, patient rights, privacy and professional rules". In most of the countries, ethics are not part of the nursing education though more than half of the participants agreed that they faced ethical situations in everyday life while working in ICU. The average scale score was lower in this study compared to other studies, this can be partially explained by the fact that most of the participants stated there is no written text about ethics as part of their education in Turkey. ${ }^{5-8}$ Comparable study was done in Iran where questionnaires were distributed to 400 ICU nurses, in effort to find causes of varying severity of ethical conflicts in ICU. Most frequent ethical conflicts were found in situations related to medical futility and dynamics of ICU environment and most intensity of ethical conflict was related to compromise and confidentiality. ${ }^{9}$

Further efforts have been put in multiple studies to find the causes of ethical conflicts and distress amongst nurses. Park et al. in the University hospital of South Korea involved 993 nurses from all departments. In this study about $68.5 \%$ were moderate and $12.1 \%$ were extremely knowledgeable whereas $37.4 \%$ and $14.7 \%$ expressed some or great need for ethics education. Causes of ethical conflict varied among the nurses working in different units in hospital. "Conflicts in nurse-physician relationship" and "providing care with a possible risk to your health" were the top two causes of ethical conflicts in all units. In ICU- "staffing pattern that limit patient access to nursing care" ranked the third cause. ${ }^{10}$ McClendon et al. did a descriptive study involving surveys to nurses to study causes of moral distress among nurses in ICU. ${ }^{11}$ Situations causing distress enumerated in survey were-critically ill patients where family wished to continue aggressive treatment, level of drug administration, withholding nutrition because patient has living

(c) The Author(s). 2022 Open Access This article is distributed under the terms of the Creative Commons Attribution 4.0 International License (https://creativecommons. org/licenses/by-nc/4.0/), which permits unrestricted use, distribution, and non-commercial reproduction in any medium, provided you give appropriate credit to the original author(s) and the source, provide a link to the Creative Commons license, and indicate if changes were made. The Creative Commons Public Domain Dedication waiver (http://creativecommons.org/publicdomain/zero/1.0/) applies to the data made available in this article, unless otherwise stated. 
will for no feeding tube and withholding mechanical ventilation because of advanced directives even if it's for short time. There were many occupation related factors that contribute to moral distress like unfriendly colleagues, insufficient nurses to staff the ICU, competency of co-workers, transferring patients from ICU when they are not ready to be transfer and physicians when they are reluctant to talk to patient's family. Gutierrez et al. suggested that cause of moral distress was lack of communication between nurses and physicians, patients and families. ${ }^{12}$ However, studies done in ICU nurses showed ethical attitudes were more positive in educated nurses and training in end of life care in ICUs have not been found to reduce moral distress. ${ }^{7,13}$

McClendon et al. also surveyed the ways of coping in their study and most common answers were talking with families about patient condition, counting to 10 , distancing oneself from the situation; joking with others, comfort in knowing that they have done all that they can do and praying. ${ }^{11}$ Gutierrez et al. on the other hand suggested following steps to help relieve moral distress in nurses (1) improving communication between healthcare team and patient family (2) improving communication between nursing and nurse management (3) developing a forum for ethical discussions (4) providing support to families with critically ill loved ones.

Can et al. study did an excellent job of understanding the ethical attitudes among ICU nurses. This is first step in understanding the problem and should be followed by further studies to understand causes of ethical conflicts and formulate steps towards solving these conflicts. Decreasing moral distress among nurses will lead to less burn out and improved job satisfaction. This can lead to fewer nurses leaving the profession and better quality of patient care. Though studies are done in past there is great variation in nursing education and patient expectations across the world which can greatly affect the study outcomes. Ethics are handled very differently across the world and such studies will certainly help bring some awareness and uniformity in different countries. This will lead to inclusion of ethics as a part of formal nursing education.

\section{OrCID}

Pritee Tarwade 이 https://orcid.org/0000-0001-5960-267X

\section{References}

1. Robert $R$, et al. Ethical dilemmas due to the Covid-19 pandemic. Annals of intensive care 2020;10(1): p. 1-9.

2. Nurses, AA. o. C.-C. AACN public policy position statement: Moral distress. Aliso Viejo, CA: American Association of Critical-Care Nurses 2004.

3. Falco-Pegueroles $A$, et al. Ethical conflict in critical care nursing: Correlation between exposure and types. Nursing ethics 2015;22(5): p. 594-607.

4. ÖZÇiFTÇi S and DE AKIN, HEMŞiRELIK BAKIMINDA ETIKTUTUM ÖLÇEĞi GELIŞTIRME.

5. Kavurmaci M and Tan M. Determining the Moral Sensitivities of Intensive Care Nurses. Critical care nursing quarterly 2019;42(3): p. 278-284.

6. Yilmaz D, et al. Examination of ethical sensitivity and related factors of nurses in internal clinics: an example of university hospital. DEUHFED 2018;11(2): p. 157-63.

7. Lusignani $\mathrm{M}$, et al. Moral distress among nurses in medical, surgical and intensive-care units. Journal of Nursing Management 2017;25(6): p. 477-485.

8. Işık MT, Özdemir RC, Serinkaya D. Ethical Attitudes of Intensive Care Nurses during Clinical Practice and Affecting Factors. Indian J Crit Care Med 2022;26(3):288-293.

9. Pishgooie $\mathrm{A}-\mathrm{H}$, et al. Ethical conflict among nurses working in the intensive care units. Nursing ethics 2019;26(7-8): p. 2225-2238.

10. Park $M$, et al. A comparison of ethical issues in nursing practice across nursing units. Nursing ethics 2014;21(5): p. 594-607.

11. McClendon $\mathrm{H}$ and EB Buckner. Distressing situations in the intensive care unit: a descriptive study of nurses, responses. Dimensions of critical care nursing, 2007;26(5): p. 199-206.

12. Gutierrez KM., Critical care nurses' perceptions of and responses to moral distress. Dimensions of Critical Care Nursing 2005;24(5): p. 229-241.

13. Henrich $\mathrm{NJ}$, et al. Consequences of moral distress in the intensive care unit: a qualitative study. American Journal of Critical Care 2017; 26(4): p. e48-e57. 